\title{
RACIAL VARIATION IN RELATION TO INFANT MORTALITY IN THE FOUR PRINCIPAL SCOTTISH TOWNS.
}

\author{
BY
}

\author{
HILDA F. MENZIES, M.D., D.P.H. \\ (From the Health Department, City of Aberdeen).
}

In the course of a detailed investigation of the infant mortality statistics of Aberdeen from 1856 to 1926 , and of the various factors which might be considered to have a bearing on this mortality, including a comparison of the conditions of life in the four principal Scottish towns, it was discovered that the infant deaths from developmental causes formed the most important group. It is proposed first to indicate briefly the general findings of the investigation before discussing in detail the mortality in the four principal Scottish towns from the group of developmental diseases, and the effect which changes in the racial composition of the towns may have had on this mortality.

Aberdeen's relatively high infant mortality in recent years has been a puzzle in Scottish infant mortality statistics. A review of the infant mortality rates of the four principal Scottish towns from 1856 to 1926 only emphasizes the problem, for in the earlier years Aberdeen had the lowest infant mortality of the four, the 1856-60 rates being Aberdeen 126, Edinburgh 146, Dundee 169, Glasgow 175. It first lost this superiority in the 1886-95 decennium, and in 1921-25 its rate is actually the highest of the four, the figures being Edinburgh 91, Glasgow 107. Dundee 113, Aberdeen 115. The Glasgow experience in infant mortality differs from that of Aberdeen, Dundee and Edinburgh, in that the trend in Glasgow shows a much more uniform fall than is the case in the other three towns. It is noteworthy also that at a period (1886-90) when the other three towns exhibited a marked increase in infant mortality, the Glasgow rate decreased considerably ; and it is interesting to find that at the period in question Glasgow was admittedly the mostinsanitary of the four towns. Indeed, an examination of the housing conditions throughout the period under review proves that Glasgow has had the greatest degree of overcrowding, both of site and of rooms, and Aberdeen the least. As regards domestic sanitation, Aberdeen is in the most favourable position of the four, and Dundee in the least.

Comparison of the birth rates of Aberdeen and Glasgow reveals the fact that Glasgow has had a higher birth rate than Aberdeen throughout the period under review, and the experience of these two towns does not, therefore, support the prevalent idea that a high hirth rate is a factor in the production of a high infant mortality. 
Analysis by age periods of the infant mortality of the four towns demonstrates that the 6-12 months age period is the only one in which there is distinct improvement in all four towns. It appears also that it is the $\mathbf{0 - 3}$ months mortality rate which establishes the superiority of Edinburgh and Glasgow over Aberdeen and Dundee. Finally, the fact that the Aberdeen 0-3 months mortality shows an increase of 7 per cent. as against a decrease in the other three towns, gives a clue as to which group of diseases is operating against the decrease of infant mortality in Aberdeen.

\section{Infant Mortality from Developmental Diseases in the Four Princi- PaL Scottish Towns (1856 to 1925).}

This group of 'developmental diseases' includes all causes which may be stated to have a pre-natal or intra-natal origin, namely premature birth, atrophy, congenital debility, marasmus, icterus, sclerema, congenital malformations, injury at birth, and other diseases peculiar to early infancy, chiefly atelectasis and diseases of the umbilicus. It has no claim to be a homogeneous group. Injury at birth, for example, has not necessarily any causal relationship with prematurity, but it is considered that the group, as a whole, forms a better basis for comparison, and at least one source of error, due to transference of causes from one sub-group to another, is eliminated. Chalmers ${ }^{1}$ illustrates the extent to which this transference appears to have occurred in Glasgow. The proportion of deaths in the first month of life ascribed to premature birth, congenital defects, and atelectasis, increased by 12 per cent. from 1903-1907 to $1908-1912$, the proportion to atrophy and debility decreased by 27 per cent., whereas the two together decreased by only $1 \cdot 4$ per cent.

Table I and Chart I show the infant mortality from the developmental group in the four principal Scottish towns from 1856-1925, in five-yearly averages.

TABLE I.

Infaxt Mortality from Group of Developmental Diseases in the Four Principal Scottish Towss, 1856-1925.

\begin{tabular}{|c|c|c|c|c|c|c|c|c|c|c|c|c|}
\hline \multirow{2}{*}{$\begin{array}{c}\text { Year. } \\
\text { Mean of : }\end{array}$} & \multicolumn{3}{|c|}{ Aberdeen. } & \multicolumn{3}{|c|}{ DUNDEE. } & \multicolumn{3}{|c|}{ EDINBURGH. } & \multicolumn{3}{|c|}{ Glasgow. } \\
\hline & $\begin{array}{l}\text { No. of } \\
\text { births. }\end{array}$ & $\begin{array}{l}\text { No. of } \\
\text { deaths. }\end{array}$ & $\begin{array}{c}\text { Mortality } \\
\text { rate. }\end{array}$ & $\begin{array}{l}\text { No. of } \\
\text { births. }\end{array}$ & $\begin{array}{l}\text { No. of } \\
\text { deaths. }\end{array}$ & $\begin{array}{c}\text { Mortality } \\
\text { rate. }\end{array}$ & $\begin{array}{l}\text { No. of } \\
\text { births. }\end{array}$ & $\begin{array}{l}\text { No. of } \\
\text { deaths. }\end{array}$ & $\begin{array}{c}\text { Mortality } \\
\text { rate. }\end{array}$ & $\begin{array}{l}\text { No. of } \\
\text { births. }\end{array}$ & $\begin{array}{l}\text { No. of } \\
\text { deaths. }\end{array}$ & $\begin{array}{l}\text { Mortality } \\
\text { rate. }\end{array}$ \\
\hline $1856-1860$ & 2,397 & 71 & $29 \cdot 6$ & 3,474 & 174 & $50 \cdot 0$ & 5,337 & 195 & $36 \cdot 5$ & 15,729 & 649 & $41 \cdot 2$ \\
\hline $1861-1865$ & 2,663 & 86 & $32 \cdot 3$ & 3,923 & 178 & $45 \cdot 3$ & 6,003 & 229 & $38 \cdot 1$ & 16,878 & 686 & $40 \cdot 6$ \\
\hline $1866-1870$ & 3,010 & 91 & $30 \cdot 2$ & 4,496 & 221 & $49 \cdot 3$ & 6,566 & 253 & $38 \cdot 5$ & 18,618 & 744 & $39 \cdot 9$ \\
\hline $1871-1875$ & 3,169 & 103 & $32 \cdot 5$ & 4,907 & 231 & $47 \cdot 0$ & 6,779 & 226 & $33 \cdot 3$ & 19,875 & 750 & $37 \cdot 7$ \\
\hline $1876-1880$ & 3,480 & 123 & $35 \cdot 3$ & 5,115 & 217 & $42 \cdot 4$ & 7,337 & 240 & $32 \cdot 7$ & 20,278 & 715 & $30 \cdot 5$ \\
\hline $1881-1885$ & 3,712 & 116 & $31 \cdot 3$ & 4,980 & 207 & $+1 \cdot 5$ & 7,263 & 235 & $32 \cdot 3$ & 19,834 & 750 & $37 \cdot 7$ \\
\hline $1886-1890$ & 3,827 & 143 & $37 \cdot 4$ & 4,719 & 223 & $47 \cdot 2$ & 7,417 & 240 & $32 \cdot 3$ & 19,456 & 707 & $36 \cdot 3$ \\
\hline $1891-1895$ & 4,114 & 155 & $37 \cdot 7$ & 4,797 & 243 & $50 \cdot 6$ & 7,318 & 255 & $34 \cdot 8$ & 22,326 & 831 & $37 \cdot 2$ \\
\hline $1896-1900$ & 4,636 & 174 & $37 \cdot 5$ & 4,822 & 221 & $45 \cdot 0$ & 8,010 & 307 & $38 \cdot 3$ & 24,153 & 983 & $40 \cdot 6$ \\
\hline 1901-1905 & 4,872 & 205 & $42 \cdot 1$ & 4,618 & 195 & $42 \cdot 2$ & 7,891 & 308 & $39 \cdot 0$ & 24,626 & 1,012 & $41 \cdot 0$ \\
\hline $1906-1910$ & 4,505 & 207 & $45 \cdot 9$ & 4,557 & 213 & $46 \cdot 7$ & 7,426 & 324 & $43 \cdot 6$ & 23,568 & 907 & $38 \cdot 4$ \\
\hline *1911-1915 & 3,959 & 201 & $50 \cdot 8$ & 4,165 & 236 & $56 \cdot 7$ & 6,282 & 274 & $43 \cdot 3$ & 25,903 & 1,126 & $43 \cdot 4$ \\
\hline $1916-1920$ & 3,479 & 188 & $53 \cdot 5$ & 3,596 & 193 & $53 \cdot 8$ & 5,775 & 253 & $44 \cdot 1$ & 26,621 & 1,111 & $41 \cdot 7$ \\
\hline $1921-1925$ & 3,763 & 201 & $53 \cdot 2$ & 4,087 & 211 & $51 \cdot 5$ & 8,541 & 316 & $37 \cdot 0$ & 27,093 & 1,027 & $37 \cdot 6$ \\
\hline
\end{tabular}


CHART I.

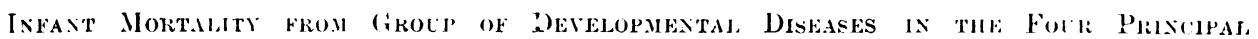
SCotrisil Towss, 1856-1925.

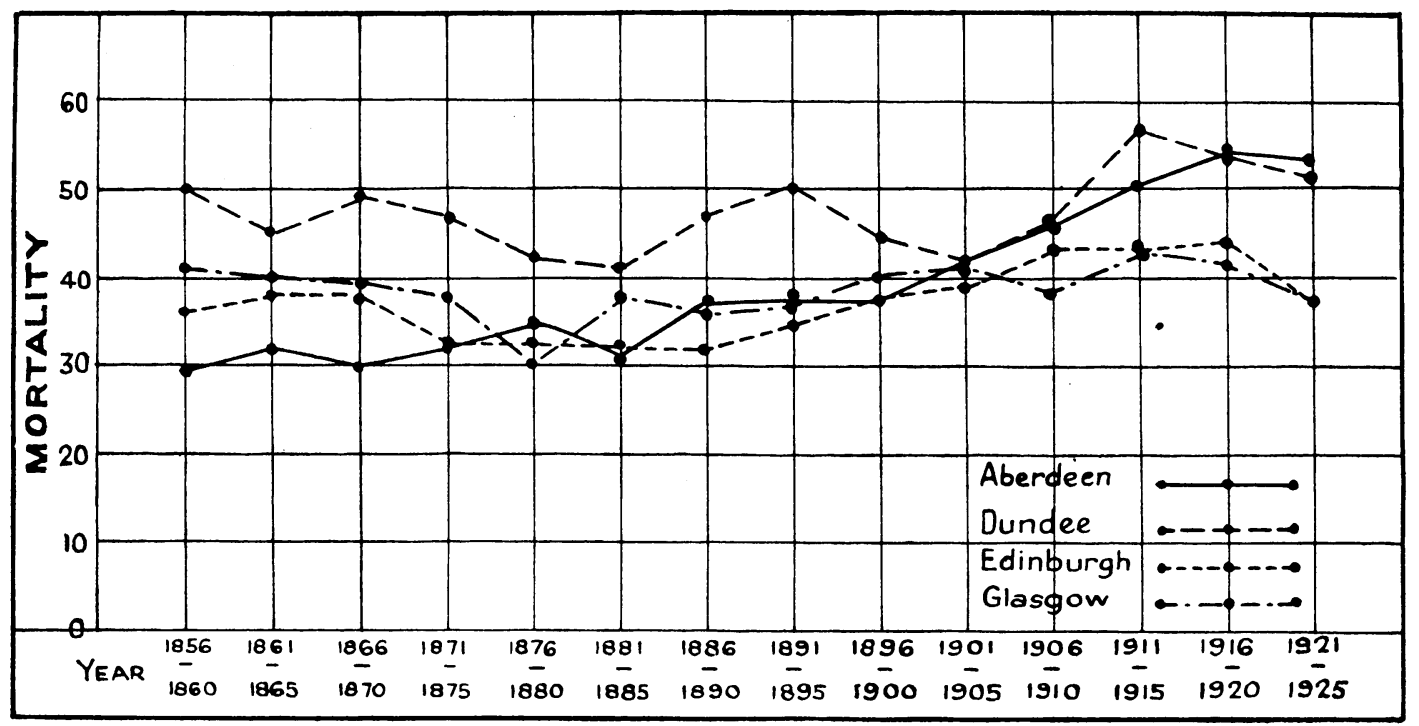

The first glance shows that the Aberdeen experience is different from that of the other three towns. Its rate starts well below any of the others, and climbs steadily until it attains the highest point of the four. Dundee and Edinburgh show a tendency to rise, but their increase is on a much smaller scale than that of Aberdeen. Thus Aberdeen increases from 29.6 in 18561860 to 53.2 in 1921-1925, an increase of 79 per cent., while Dundee increases from 50.0 to 51.5 , and Edinburgh from 36.5 to 37 , representing increases of 3 per cent. and 1 per cent. respectively. Glasgow is the only town which shows a decrease over the whole period, from $41 \cdot 2$ in $1856-1860$ to $37 \cdot 6$ in 1921-2.5, a decrease of 9 per cent.

In the earlier years there is a difference of $6-9$ between Aberdeen and the next lowest town, Edinburgh, their values in 1866-1870 being $30 \cdot 2$ and 38.5 respectively. The following quinquenniad marks the beginning of Aberdeen's upward trend, the rate in 1871-1875 reaching 32.5 , which approximates the Edinburgh rate of $33 \cdot 3$. A further rise for Aberdeen in 1876-1880 to 35.3 takes it above both the Edinburgh and Glasgow figures, Edinburgh maintaining an almost constant level for twenty years, and Glasgow having fallen from 37.7 in $1871-1875$ to 30.5 in $1876-1880$. In $1886-1890$ Aberdeen rises fairly sharply again to $37 \cdot 4$, which was Glasgow's figure in 1881-1885, and from that point the two rates run a similar course up to the end of the century. In 19011905 Aberdeen has reached 42.1, and Glasgow 41.0. The Edinburgh rate has been rising since 1891-1895 and in 1901-1905 it stands at 39.0. Meanwhile Dundee has maintained a fluctuating and distinctly higher rate; beginning at 50 in $1856-1860$ it descends to 41.5 in $1881-1885$, rises to $50 \cdot 6$ in 1891-189.5, 
and in 1901-1905 it falls for the first time to Aberdeen's level of 42.2. From that time the Aberdeen and Dundee rates behave similarly, both rising markedly, being unlike only in that the Dundee apex is reached in 1911-1915, at $56 \cdot 7$, the rate falling subsequently to $51 \cdot 5$ in $1921-1925$, while the Aberdeen rise continues until 1916-1920 to 53.5, and there is practically no fall in 19211925. The Edinburgh and Glasgow rates show less variation from 1901-05 to 1916-20, although Edinburgh rises 5 points in the fifteen years, and both towns exhibit a distinct improvement in the 1921-1925 quinquenniad, Edinburgh falling from $44 \cdot 1$ to $37 \cdot 0$, and Glasgow from $41 \cdot 7$ to $37 \cdot 6$.

Table IA $_{\mathrm{A}}$ and Chart IA are complementary to Table I and Chart I. Table I and Chart I show the rates of infant mortality from the developmental group of the four towns; Table IA and Chart IA deal with the values of $\frac{x-x}{\sigma x}$ where $x=$ the value of the variate, the infant mortality from the developmental group per 1,000 live births for any period;

$\bar{x}=$ the mean value of $x$;

$\sigma x=$ the standard deviation of the distribution of $x$.

The expression $\frac{x-\bar{x}}{\sigma x}$ therefore shows the deviation of the infant mortality for each period, compared with its own variability as measured by the standard deviation. Distributions of infant mortality per 1,000 births for the various towns can thus be compared, as they are all reduced to a common standard deviation of unity.

TABLE IA.

Values of $\frac{x-\bar{x}}{\sigma x}$. Four Principal Scotrish Towns (1856-1925).

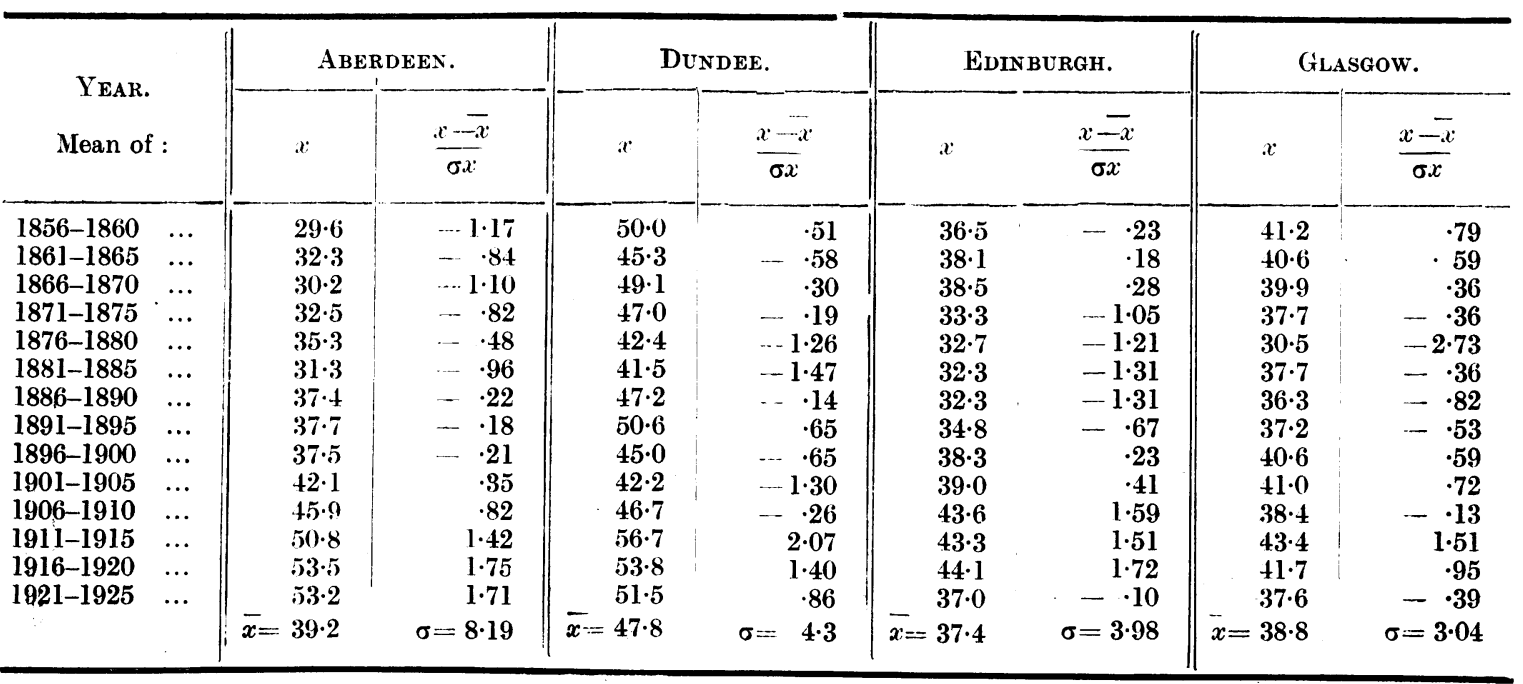

$x=$ infant mortality from group of developmental diseases.

$\bar{x}=$ mean of $x$

$\sigma x=$ standard deviation of $x$. 


\section{CHART 1 A.}

Values of $\frac{x-x}{\sigma x}$. Four Principal scuttish Towns (1856-1925).

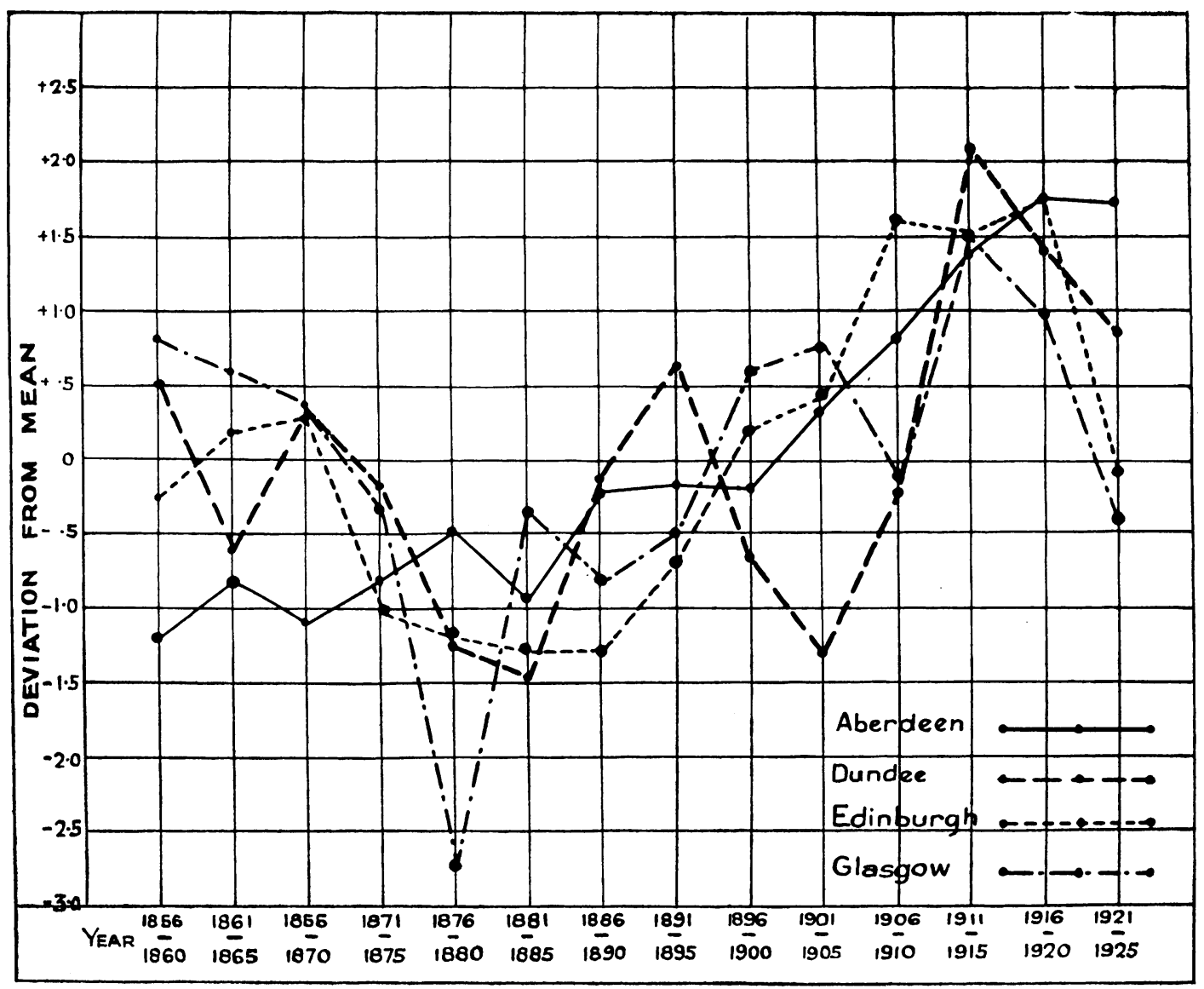

$\underline{x}=$ infant mortality from group of developmental diseases.

$\bar{x}=$ mean of $x$.

$\sigma x=$ standard deviation of $x$.

It is seen that Aberdeen exhibits the greatest variability, for while there is little difference in the means of Aberdeen, Edinburgh, and Glasgow, the figures being $39.2,37.4$ and 38.8 respectively, the standard deviations are 8.19 for Aberdeen, 3.98 for Edinburgh, and 3.04 for Glasgow. Dundee has a mean of $47 \cdot 8$ with a standard deviation of $4 \cdot 3$.

The steady and almost continuous rise of the Aberdeen rate is accentuated in this chart. Thus its values for 1856-1900 are all negative (i.e. below the mean) from $-1 \cdot 17$ in 1856.1860 to -.21 in 1896-1900, and from 1901-1925, its values are all positive (i.e. above the mean) and increase steadily in amount, reaching 1.71 in 1921-1925. Dundee and Glasgow start above their respective means in 1856-1860, Dundee with a value of .51 , and Glasgow with a value 
of $\cdot 79$. Edinburgh sets off with a negative value $-\cdot 23$, but by $1866-1870$ there is little difference between the three towns, Dundee being at $\cdot 3$; Edinburgh $\cdot 28$, and Glasgow $\cdot 36$. The corresponding figure for Aberdeen is $-1 \cdot 1$. The following 30-35 years mark a period of low values for Dundee, Edinburgh and Glasgow. All fall considerably below their means, but Glasgow reaches its lowest point in 1876-1880 at -2.73 , Dundee's lowest value is -1.47 in 1881-1885, five years later, while Edinburgh continues to fall until 1886-1890 when its value is -1.31. At this period the Aberdeen value has reached -.18. All four towns now enter on a period of increasing values, and the resemblance between the experience of each town is marked (which was less obvious in the graph of the actual death rates), although Dundee shows a fall to $-1 \cdot 3$ in 19011905, which is not repeated in the other three towns. Glasgow, again, falls to - $\cdot 13$ in 1906-1910, after a value of $\cdot 72$ in 1901-1905. The rate of increase in all four towns is such that in 1911-1915 Aberdeen $=1 \cdot 42$, Dundee $=2.07$, Edinburgh $=1.51$, and Glasgow $=1.51$. For Dundee and Glasgow this represents their highest point, and by 1916-1920 Dundee has fallen to $1 \cdot 4$, and Glasgow to 95 . Aberdeen and Edinburgh continue to rise to their respective maxima in 1916-1920, 1.75 for Aberdeen, and 1.72 for Edinburgh. In the final quinquenniad, 1921-1925, Edinburgh follows the lead of Dundee and Glasgow in a rapid fall, the values being $\cdot 86$ for Dundee, $-\cdot 10$ for Edinburgh, and $-\cdot 39$, for Glasgow, and Aberdeen is left in an isolated position 1.71 above its mean.

The exact significance is doubtful, but it is clear that the early advantage which Aberdeen exhibited over the other three Scottish towns in regard to infant mortality has been lost largely by reason of the alarming increase in mortality from developmental diseases shown by Aberdeen, against the almost stationary or even decreasing rate of the other towns.

It may be suggested that Aberdeen's increase may be partly due to a change in nomenclature whereby deaths formerly classified 'from unknown or ill-' defined causes' are now included in the developmental group, but as this increase is not evident to the same extent in the other three towns, such a suggestion implies that the Aberdeen practitioner is an isolated product in the matter of improved diagnosis of developmental errors, a conclusion which is hardly justified.

In order to afford a rough test of the extent to which the increase in 'developmental' deaths in Aberdeen is an apparent one, due to changes in classification I have calculated (Table IIA) for four random years throughout the pericd (1) the percentage of developmental deaths which occur under 3 months; this is found to be $90-93$ per cent. until 1901, while in 1921 it has fallen to 81 per cent.; (2) the percentage distribution of the $0-3$ months deaths due to developmental diseases, bronchitis and pneumonia, digestive diseases, convulsions, and other causes. Again, the percentage due to developmental diseases remains fairly constant, about 50 per cent. until 1901, and the decrease in the percentage of deaths from 'other causes' from 23 per cent. in 1867 to 17 per cent. in 1901, appears to be reflected more in the rates from bronchitis 
and pneumonia, digestive diseases and convulsions, all of which claim a larger share. In 1921, the percentage due to developmental diseases has risen to $66 ;$ of the total 0-3 months deaths, while the percentage of 'other causes' has fallen from 17 to 11 , bronchitis and pneumonia from 11 to 9 , digestive diseases from 10 to 7 , and convulsions from 10 to 7 . This suggests a transference to some extent, but it must be remembered that the total $0-3$ months mortality has fallen during this period, and the natural result would be a higher proportion of deaths from the cause least amenable to post-natal preventive measures.

TABLES IIA AND IIB.

\begin{tabular}{|c|c|c|c|c|c|c|c|c|}
\hline & \multicolumn{2}{|c|}{1867} & \multicolumn{2}{|c|}{1883} & \multicolumn{2}{|c|}{1901} & \multicolumn{2}{|c|}{1921} \\
\hline (A) & Aber & deen. & Aber & een. & Aber & leen. & Aber & deen. \\
\hline $\begin{array}{l}\% \text { of Developmental Deaths which } \\
\text { occurred from 0-3 months }\end{array}$ & \multicolumn{2}{|c|}{93} & \multicolumn{2}{|c|}{90} & \multicolumn{2}{|c|}{93} & \multicolumn{2}{|c|}{81} \\
\hline $\begin{array}{l}\% \text { of Deaths under } \\
3 \text { months due to :- }\end{array}$ & & & & & & & & \\
\hline Developmental Group $\quad \ldots$ & \multicolumn{2}{|c|}{53} & \multicolumn{2}{|c|}{47} & \multicolumn{2}{|c|}{52} & \multicolumn{2}{|c|}{66} \\
\hline Bronchitis and Pneumonia & \multicolumn{2}{|c|}{9} & \multicolumn{2}{|c|}{12} & \multicolumn{2}{|c|}{11} & \multicolumn{2}{|c|}{9} \\
\hline Digestive Diseases... $\quad \ldots$ & \multicolumn{2}{|c|}{8} & \multicolumn{2}{|c|}{12} & \multicolumn{2}{|c|}{10} & \multicolumn{2}{|c|}{7} \\
\hline $\begin{array}{lll}\text { Convulsions } & \ldots & \ldots\end{array}$ & \multicolumn{2}{|c|}{8} & \multicolumn{2}{|c|}{ Il } & \multicolumn{2}{|c|}{10} & \multicolumn{2}{|c|}{7} \\
\hline $\begin{array}{llll}\text { Other } & \ldots & \ldots & \ldots\end{array}$ & \multicolumn{2}{|c|}{23} & \multicolumn{2}{|c|}{18} & \multicolumn{2}{|c|}{17} & \multicolumn{2}{|c|}{11} \\
\hline (B) & $\begin{array}{l}\text { Aber- } \\
\text { deen. }\end{array}$ & $\begin{array}{l}\text { Glas. } \\
\text { gow. }\end{array}$ & $\begin{array}{l}\text { Aber- } \\
\text { deen. }\end{array}$ & $\begin{array}{l}\text { Glas- } \\
\text { gow. }\end{array}$ & $\begin{array}{l}\text { Aber - } \\
\text { deen. }\end{array}$ & $\begin{array}{l}\text { Glas- } \\
\text { gow. }\end{array}$ & $\begin{array}{l}\text { Aber- } \\
\text { deen. }\end{array}$ & $\begin{array}{l}\text { Glas- } \\
\text { gow. }\end{array}$ \\
\hline $\begin{array}{l}\% \text { of Developmental Deaths which } \\
\text { occur from } 0-3 \text { months ... }\end{array}$ & 93 & 88 & 90 & 89 & 93 & 91 & 81 & 88 \\
\hline $\begin{array}{l}\% \text { of } 0-3 \text { month Deaths due to } \\
\text { Developmental Group } \ldots\end{array}$ & 53 & 51 & 47 & 53 & 52 & $\tilde{5} 4$ & 66 & 63 \\
\hline $\begin{array}{l}\% \text { of infant deaths due to Unspeci- } \\
\text { fied causes } \\
\end{array}$ & () & 4 & 1 & 1 & 1 & 2 & 0 & $\cdot 4$ \\
\hline
\end{tabular}

(A) Proportion of Developmental deaths which occur under 3 months, and

Proportion of Aberdeen, 1867, 1883, causes.

1901, 1921 .

(в) Proportion of Developmental deaths which occur under 3 months, proportion of 0-3 months deaths due to Developmental group, and proportion of infant deaths due to unspecified causes, Aberdeen, and Glasgow, 1867, 1883, 1901. 1921 .

A comparison between Aberdeen and Glasgow on similar lines (Table IlB) giving, (1) percentage of developmental deaths occurring under 3 months; (2) percentage of 0-3 months deaths due to developmental diseases; (3) percentage of total infant deaths due to unspecified causes, shows that until 1901 there was very little difference between the two towns. In 1921 the 
percentages of the total deaths under 3 months due to developmental causes still correspond in the two towns, but the Glasgow percentage of developmental deaths which occur under 3 months has decreased only from 91 to 88 , while the Aberdeen percentage has decreased from 93 to 81 . The percentage of infant deaths due to unspecified causes is not large enough in either town to be of any moment.

The evidence afforded does not support the suggestion that the increase in the Aberdeen infant mortality from developmental causes is more apparent than real. The most that can be said is that in Aberdeen in the last twenty vears a larger proportion of deaths occurring over 3 months are certified as developmental than is the case in Glasgow. This may mean either that a larger proportion of such children survive the 3 months age period in Aberdeen, or that there is a certain amount of difference of certification in the two towns.

\section{Racial Composition of Towns.}

Certain facts relative to the influence of heredity seem worthy of discussion. We have seen that: over the seventy years studied, the environmental conditions of the four principal Scottish towns are at their worst in Glasgow, and at their best in Aberdeen : moreover, the period during which Glasgow was the only town of the four able to show a decrease in infant mortality was the very period at which it was undoubtedly 'the unhealthiest town in Scotland.' Huntington ${ }^{2}$ writes :-

The geographer and œecologist insist that history must be interpreted in terms of environment. the historian insists that it must be interpreted in terms of events and personalities, the anthropologist insists on an interpretation in terms of races. All are right. for what is needed is a synthesis of the various points of view. The character of any race is a function partly of the present enviromment, and partly of countless past environments which have selected first one type and then another for preservation, and thus have played a large part in moulding racial character.

\section{(a) Influence of racial variation on infant mortality.}

The influence of change in the racial composition of the population of the city of New York, due to the large stream of immigration, on the infant mortality, has been studied by Meyer ${ }^{3}$. The infant mortality for the year 1915 . including all races, was $98 \cdot 2$. For children of American parents it was 106.3, for Italians 103.2, for Austro-Hungarians 79.8, and for Russian Poles 77.9. The last two are almost entirely Jews. Guilfoy ${ }^{4}$ produces a table of infant mortality from congenital diseases, grouped according to the nationality of the mother, for the Borough of Manhattan, in the year 1915. Each group deals with from $9,000-17,000$ births, and the rates are 54.4 per 1,000 births where the mother is American, 32.0 in the case of Russian parentage, 28.4 for AustroHungarians, and 29.5 for Italians. Meyer $^{3}$ found that the influence of the racial factor was most marked in the groups of diarrhoal and congenital diseases. He remarked that Russians, Poles, Austrians, and Italians had entered America in increasing numbers from year to year, especially since 1900, 
and he decided that the increase in the foreign element of the city had tended to accelerate the rate of decline of the infant mortality rate. Little ${ }^{5}$ publishes an interesting study from records (including still-births) of a lying-in hospital in New York. The types of mating included (1) those within each of the following nationalities, English, Irish, Scottish, Italian, Russian, Greek, Austrian, and German, (2) all possible first generation matings between members of these nationalities. The results give a markedly higher ratio of male births in the hybrid stock, and a separate examination of the still-birth data indicated that they were more frequent in the pure races than in the crosses. As the latter fact was tested only for first generation matings Little suggests that the lower frequency of still-births in the crosses was probably a result of hybrid vigour. In the census report (1871) for Scotland ${ }^{6}$ it was noted that emigration increased the fertility of women for the first generation.

In De Porte's ${ }^{7}$ study of inter-racial variation in infant mortality he decided that ' the racial groups whose infants suffer more from environmental defects, suffer less from causes that are mainly dependent upon the child-bearing mechanism of the mother. Economic and social conditions have little effect upon this period of infant mortality. Here nature plays no favourites, and non-viable and malformed infants are equally frequent among the rich and the poor.' Forbes ${ }^{8}$, dealing with the statistics of Brighton from 1901-1920, commented on the fact that there was very little difference in the $0-1$ month death rate in the different social groupings. On the other hand, Chalmers' inquiry in Glasgow, representing the average experience of the three years 1909-1912, suggested a grading of the immaturity death rates in correspondence with the general death rate, i.e., they were higher in the poorer districts.

(b) Changes in racial composition of the four principal Scottish towns from 1871.

The 1871 census report contains a discussion on the races of men in Scotland which has sufficient relevance to deserve full quotation.

Some knowledge of the races of men who inhabit a country has always been deemed of importance when considering the statistics of its population. The lowlands are inhabited by that mixed race to which the term Anglo-Saxon is now generally applied. This is an energetic race, sprung from a mixture of all the various nations which have invaded the country and settled among its original inhabitants, the Goths, Romans, Gauls or Celts, Saxons, Danes, Normans, and Norsemen from Norway and Sweden.

The whole of the highland portion has as its leading inhabitants a nearly pure Celtic race still retaining their ancient language and showing in their configuration and general character the peculiarities of that race.

A race, however, of nearly pure Norsemen, originally from Norway and Sweden, now constitute the majority of the inhabitants of Orkney and Shetland, of the county of Caithness, and of a great many of the fishing villages on the northern and eastern coasts of Scotland, even down to the fishing villages of Buckie, and Newhaven in the Firth of Forth.

Till the year 1820 these were the three races of men in Scotland, but during that year an invasion or immigration of the Irish race began, which slowly increased till it attained enormous dimensions after 1840. This invasion of the Irish is likely to produce far more serious effects on the population of Scotland than even the invasions of warlike hordes of Saxons, Danes, or Norsemen. Already in many of our towns do the persons born in Ireland constitute from 
5-15 per cent. of the population; and if we include their children, born in this country, from 10-30 per cent. of the population of these towns consists of the Irish Celtic race. The immigration of such a body of labourers of the lowest class, with scarcely any education, cannot but have most prejudicial effects on the population. As yet the great body of these Irish do not seem to have improved by their residence among us; and it is quite certain that the native Scot who has associated with them has most certainly deteriorated. It is painful to contemplate what may be the ultimate effect of this Irish immigration on the morals and habits of the people and on the future prospects of the country."

In the same report (1871) it is noted that while Shetland is the worst housed county in Scotland, 90 per cent. of her population living in houses of one or two rooms with or without windows, 'so many crude and unsupported theories are now brought forward and proclaimed as facts that it seems right to mention that she stands pre-eminent for the healthiness of her population, and also for their morality ; which leads us to conclude that house accommodation is only one of the causes, and after all perhaps not one of the most important, which affects the healthiness and morality of a people.'

Table III, prepared from the census reports, shows the proportion of Scottish, Irish and Foreign born, in the populations of Aberdeen, Dundee, Edinburgh and Glasgow from 1871-1921. It will be noted that the Aberdeen population is the purest race of the four, 95 per cent. of her population being Scottish born ; Glasgow is the most hybrid, only 83 per cent. of her population in 1881 being Scottish born, although by 1921 the percentage has risen to 88 : Dundee and Edinburgh are intermediate, Edinburgh being the more hybrid of the two, with an average percentage of 90 Scottish born; Dundee had 89 per cent. of Scottish born in her popultion in 1881, but the rate of immigration decreased at the beginning of the century, and in 1921, 95 per cent. of the population was Scottish born. The largest non-Scottish element was due to the Irish 'invasion' commented on so unfavourably in the 1871 census report. In Glasgow the proportion of Irish born was as high as 14 per cent. in 1871, compared with 11 per cent. in Dundee, 4 per cent. in Edinburgh, and .9 per cent. in Aberdeen. The rate of Irish immigration was continued to a greater extent in Glasgow than in the other three towns. In 1921, the percentage of Irish born in Glasgow was $6 \cdot 4$, in Edinburgh it was only 1.5, in Dundee 1.4, and in Aberdeen $\cdot 3$.

In regard to the foreign population, apart from the Irish, Glasgow has again the highest proportion, Edinburgh comes second and Dundee and Aberdeen have never more than $\cdot 2-4$ per cent. The Glasgow percentage varies from two to five times the Aberdeen percentage.

When the children of the foreign population, born in Scotland, are included, the percentage of foreign stock (including Irish) in Glasgow is seen to be very great. Tocher ${ }^{10}$ found that in 1901,42 per cent. of the total number of foreigners in Scotland resided in Glasgow alone, and that the most densely populated part of the city contained a larger proportion of foreigners than the less densely populated parts ; in fact that the foreign element resided largely in the districts of one- and two-roomed houses. Levy ${ }^{11}$ commented on the fact 
that the lowest still-birth and neo-natal mortality rates were found in foreign mothers whose economic social and housing conditions would naturally be held to be unfavourable.

An additional point of interest in Tocher's survey is that the foreigners in Glasgow are mostly Jews, 60 per cent. Russian and Polish, and 15 per cent. Italian. The Jewish infant mortality is known to be low. Hertz ${ }^{12}$ states that it is only half that of the general population, and among the poorer class Jews even less. He mentions two factors which may contribute to this low mortality, (1) the mothers invariably nurse their children, (2) the total absence of alcoholism among Jewish women. The disfavour with which the Rabbis regard marriage of the physically unfit, or of those with a family history of transmissible disease may be an even more potent factor.

TABLE III.

Proportion of Scoteish, Irish and Foreign-born in populations of Folr Principal ScotTish Towns, 1871-1921.

\begin{tabular}{|c|c|c|c|c|c|c|c|c|c|c|c|c|c|c|c|c|}
\hline \multirow{2}{*}{ Year. } & \multicolumn{4}{|c|}{ Aberdeen. } & \multicolumn{4}{|c|}{ Dundee. } & \multicolumn{4}{|c|}{ Edinburgh. } & \multicolumn{4}{|c|}{ Glasgow. } \\
\hline & $a$ & $b$ & $c$ & $d$ & $a$ & $b$ & $c$ & $d$ & $a$ & $b$ & c & $d$ & $a$ & $b$ & $c$ & $d$ \\
\hline 1871 & 88 & - & $\cdot 9$ & - & 120 & - & 11 & - & 201 & - & 4 & - & 478 & - & 14 & - \\
\hline 1881 & 105 & 96 & $\cdot 7$ & $\cdot 2$ & 142 & 89 & 8 & $\cdot 2$ & 234 & 89 & 4 & $\cdot 4$ & 511 & 83 & 13 & $\cdot 4$ \\
\hline 1891 & 122 & 95 & $\cdot \tilde{5}$ & $\cdot 2$ & 155 & 91 & 5 & $\cdot 2$ & 261 & 91 & 3 & $\cdot 4$ & 566 & 85 & 10 & -4 \\
\hline 1901 & 154 & 95 & $\cdot 4$ & $\cdot 2$ & 163 & 93 & 3 & $\sqrt{2}$ & 317 & 90 & 2 & 6 & 776 & 85 & 9 & 1 \\
\hline 1911 & 164 & 95 & $\cdot 3$ & $\cdot 3$ & 165 & 94 & 2 & $\cdot 3$ & 320 & 90 & $1 \cdot 6$ & $\cdot 7$ & 784 & 88 & $6 \cdot 7$ & 1 \\
\hline 1921 & 159 & 95 & $\cdot 3$ & $\cdot 3$ & 168 & 95 & $1 \cdot 4$ & $\cdot 4$ & 420 & 89 & $1 \cdot 5$ & $\cdot 7$ & 1034 & 88 & $6 \cdot 4$ & $\cdot 9$ \\
\hline
\end{tabular}

Brownlee $^{13}$ finds that a free mating population becomes stable on a Mendelian hypothesis, in one generation, but that differences of religion check intermarriage, and where Roman Catholics and Protestants inhabit the same valley they keep.themselves more or less apart, and slightly different types develop within the same region. Towns also afford an exception and he states that immigration into these has been so marked in the last sixty years (before 1911) that there is not yet time for the production of a homogenous race mixture, and in these centres especially, religion has proved a bar to free intermarriage.

One marked difference has therefore been discovered between the constitution of the Glasgow population and that of the other three principal Scottish towns. Glasgow contains a much larger proportion of Irish and Jews, both of which races are known to have a low infant mortality, than exists in any other town in Scotland. The evidence submitted from towns where analyses of the effect of a foreign element in the population have been made, suggests that immigrating stock adds vigour to the native stock, and that a lowered infant mortality results, the deaths from developmental diseases being the group which is mainly affected. The data are insufficient to prove the exact effect 
of immigration on the Glasgow infant mortality. It would be curious if the increasing number of Irish in Glasgow, which has been so much deplored, should be found to have accelerated the decrease in infant mortality, which has been deemed a matter for congratulation.

The English Registrar-General's note in his Statistical Review ${ }^{14}$ that the mortality from premature births varies much more with the geographical section of the country than with the degree of urbanization, is worth recording. Taking the country as a whole the excess of North over South is 29 per cent., but that for the county boroughs over the rural districts is 13 per cent. My findings do not lead me to agree with his conclusion that 'these facts would seem to accentuate the possibility of further reduction in the neo-natal mortality, as it should be more feasible to approximate the conditions of fœtal and infant life in the North to these prevailing in the South, than to overcome for the great towns their disadvantages as compared with the rural districts.' The very fact that the infant mortality from this cause varies more with the geographical section of the country than with the degree of urbanization suggests that urbanization is not the dominant factor in producing this mortality.

It has been found that while Aberdeen has been ahead of the other three principal Scottish towns in housing and sanitary reform, and has never suffered the same degree of congestion as Glasgow and Dundee, nevertheless the rate of decrease of infant mortality in Aberdeen has been considerably less than in any of the other three towns. Further, if the mortality rates from separate causes are to be regarded as having any significance, it is to the group of developmental diseases that we must look for a solution of the problem.

\section{(c) ('omparison of Mortality rates from the Group of Developmental Disenses in the County of Aberdeen, and in the Toun of Aberdeen, 1856-1925.}

The fact that 95 per cent. of the population of Aberdeen is Scottish, and that 75 per cent. are born in Aberdeenshire, led me to investigate the infant mortality from the developmental group in the County of Aberdeen.

In the reports of the Registrar General (Scotland), mortality tigures for counties are distributed either according to age or according to disease, but not for the two simultaneously. Accordingly, it was not possible to obtain the absolute number of deaths under one year from the developmental group in the County of Aberdeen. Deaths certified as due to congenital malformations, prematurity or atelectasis, may safely be taken as occurring under one year, but in the case of deaths from atrophy or debility, a number occur in the second year, or even later. To obtain a fair estimate I referred in each year to the deaths from these causes in the town of Aberdeen, noted what proportion occurred under one year and allowed a similar proportion in calculating the death rate of the developmental group, in the county. The figure is as accurate as can be obtained under the circumstances, and reference to Table IV shows how closely it follows the trend of the mortality from the same causes in the 
TABLE IV.

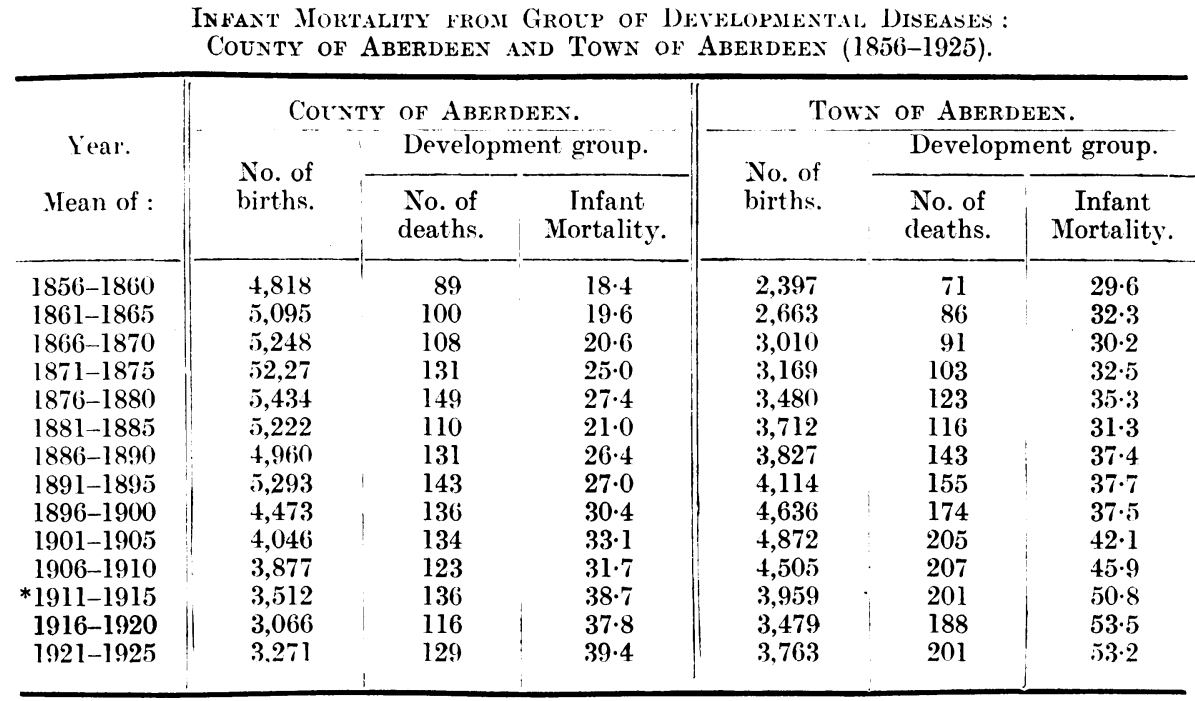

* Corrected for transfers from 1911.

town of Aberdeen. The county rate has risen from 18.4 in 1856-1860 to 39.4 in 1921-1925, an increase of practically 90 per cent. The parallel fall in town and county rates in the 1881-1885 period, and the subsequent rise in both is striking. The correspondence in more recent years is less marked, but there is a sufficient degree of resemblance to suggest a defect common to the two populations. What is the nature of the defect must be a matter for speculation until the data necessary for its solution are extended and elaborated.

The hypothesis that Aberdeen (both town and county) is breeding to an increasing extent from that portion of her population which suffers from developmental defects, must be considered.

\section{Summary and Conclusions.}

Group of Developmental Diseases.--Examination of the infant mortality from the group of developmental diseases in the four principal Scottish towns from 1856-1926 shows that the mortality from this cause has increased by 79 per cent. in Aberdeen, by 3 per cent. in Edinburgh, and by 1 per cent. in Dundee, while the Glasgow mortality has decreased by 9 per cent. It seems clear that the early advantage which Aberdeen exhibited over the other three Scottish towns in regard to infant mortality has been lost largely by reason of its alarming increase in mortality from developmental diseases. As far as can be judged the increase is real rather than apparent.

The Racial Factor and Infant Mortality.--Meyer decided that the increase in the foreign element in the New York population had tended to accelerate the rate of decline of infant mortality, and other observers have noted the increased vigour of hybrid stock, with a diminution in infant mortality affecting particularly the deaths from developmental diseases. 
No data are available to prove the effect of this racial factor on the Scottish infant mortality statistics, but it is notable that the town which has shown the steadiest rate of decrease in infant mortality, namely Glasgow, is the town of most hybrid stock, and that the town possessing the purest race (Aberdeen) is also the town where there has been least decrease in infant mortality. It is interesting, also, to find that the trend of infant mortality from developmental diseases in the County of Aberdeen, from 1856-1926, shows a striking parallelism with the mortality from the same group in the town of Aberdeen, although at a lower level.

\section{REFERENC'ES.}

1. Chalmers, A. K., Rep. M.O.H. Glasgow for 1913. Appendix III, Glasgow, 1914, 226.

2. Huntington, E., Organic Adaptation to Environment. Newhaven, 1924, 299.

3. Meyer, E. C., Internat. Hlth. Bd. Ser., N.Y. 1921, X, 36.

4. Guilfoy, W. H., N.Y. City Dept. Hlth., Mon. Ser. XVIII, N.Y., 1917.

5. Little, C. C., Proc. Soc. Exp. Biol. Med., N.Y., 1919, XVI, 127.

6. Report of Census of Scotland for 1871, Edinburgh (1872) II, LXIII, 197.

7. De Porte J. V., Am. J. Hyg., Baltimore, 1925, V, 454.

8. Forbes, D., Lancet, Lond., 1922, i, 426.

9. Chalmers, A. K., Rep. M.O.H., Glasgow for 1913. Appendix III. Glasgow, 19] 4, 229.

11). Tocher, J. F., Biometrika, Lond., 1908, VI, 130.

I1. Levy, J., Trans. Am. Ch. Hyg. Ass., 1922, quoted by E. Blanche Sterling, Pub. Hlth. Re ${ }_{1}^{\prime}$, Washington, 1927, XIII, si, 740.

12. Hertz, J. H., Rep. Conf. Mat. \& Ch. Welf., Lond., 1926, 128.

13. Brownlee, J., J. Roy. Anthropol. Inst., Lond. 1911, XLI, 183.

14. English Registrar-General's Statistical Rerieu for 1924, 'Text., Iond. 1926. New Annual Scries TV. 18. 